\title{
A Molecular Defect in Hepatic Cholesterol Biosynthesis in Sitosterolemia with Xanthomatosis
}

\author{
Lien B. Nguyen, Sarah Shefer, Gerald Salen, Gene C. Ness, G. S. Tint, F. George Zaki, and Indu Rani \\ Department of Medicine and the Sammy Davis Jr. National Liver Institute, University of Medicine and Dentistry-New Jersey Medical \\ School, Newark, New Jersey 07103; Gastroenterology Section, Veterans Administration Medical Center, East Orange, New Jersey
}

07019; and Department of Biochemistry and Molecular Biology, College of Medicine, University of South Florida, Tampa, Florida 33612

\begin{abstract}
We examined the relationship between cholesterol biosynthesis and total and high affinity LDL binding in liver specimens from two sitosterolemic and 12 healthy control subjects who died unexpectedly and whose livers became available when no suitable recipient for transplantation was identified. Accelerated atherosclerosis, unrestricted intestinal sterol absorption, increased plasma and tissue plant sterol concentrations, and low cholesterol synthesis characterize this disease. Mean total microsomal HMG-CoA reductase (rate-control controlling enzyme for cholesterol biosynthesis) activity was sevenfold higher (98.1 $\pm 28.8 \mathrm{vs}$. $15.0 \pm 2.0 \mathrm{pmol} / \mathrm{mg}$ protein per $\mathrm{min})$ and microsomal enzyme protein mass was eightfold larger $(1.43 \pm 0.41$ vs. $0.18 \pm 0.04$ relative densitometric $U / \mathrm{mg}$ protein) in 11 controls than the average for two sitosterolemic liver specimens. HMG-CoA reductase mRNA probed with pRED 227 and pHRED 102 was decreased to barely detectable levels in the sitosterolemic livers. In addition, there was a $50 \%$ decrease in the rate $\left[2-{ }^{14} \mathrm{C}\right] \mathrm{mevalonic}$ acid was converted to cholesterol by sitosterolemic liver slices compared with controls (112 vs. $224 \pm 32 \mathrm{pmol} / \mathrm{g}$ liver per $\mathrm{h})$. In contrast, average total LDL binding was $60 \%$ greater (326 vs. $204 \pm 10 \mathrm{ng} / \mathrm{mg}$ ), and high affinity (receptor-mediated) binding $165 \%$ more active ( 253 vs. $95.1 \pm 8.2 \mathrm{ng} / \mathrm{mg}$ ) in two sitosterolemic liver membrane specimens than the mean for 12 controls. Liver morphology was intact although sitosterolemic hepatocytes and microsomes contained 24 and $14 \%$ less cholesterol, respectively, and 10-100 times more plant sterols and 5 $\alpha$-stanols than control specimens.
\end{abstract}

We postulate that inadequate cholesterol biosynthesis is an inherited abnormality in sitosterolemia and may be offset by augmented receptor-mediated LDL catabolism to supply cellular sterols that cannot be formed. (J. Clin. Invest. 1990. 86:923-931.) Key words: liver HMG-CoA reductase activity • mass $\bullet$ mRNA and LDL receptors

\section{Introduction}

Sitosterolemia with xanthomatosis is a rare inherited lipid storage disease that was first described by Bhattacharrya and

\footnotetext{
Address reprint requests to Dr. Gerald Salen, GI Research Lab (111), VA Medical Center, East Orange, NJ 07019.

Received for publication 26 January 1990 and in revised form 18 May 1990.
}

J. Clin. Invest.

(C) The American Society for Clinical Investigation, Inc. 0021-9738/90/09/0923/09 \$2.00

Volume 86, September 1990, 923-931
Connor in 1974 (1). Tendon and tuberous xanthomas, accelerated atherosclerosis, hemolytic episodes, and painful arthritis and arthralgias are typical clinical manifestations, while the accumulation of plant sterols and lesser amounts of $5 \alpha$-stanols in all tissues except brain are major biochemical features (2-4). Plasma sterol concentrations fluctuate but are usually elevated because of the abundance of plant sterols and $5 \alpha$-stanols. Intestinal absorption of plant sterols, which is normally restricted, is increased markedly and approaches that of cholesterol $(1,5-8)$ while $5 \alpha$-cholestanol, $5 \alpha$-campestanol, and $5 \alpha-$ sitostanol are formed endogenously from their respective unsaturated sterol precursors (4).

Whole body cholesterol turnover and synthesis determined by sterol balance and isotope kinetic techniques in four sitosterolemic subjects from three unrelated families were $50-80 \%$ less than similarly fed control subjects $(5,8,9)$. Further, reduced cholesterol synthesis was related to a severe deficiency of HMG-CoA reductase in freshly isolated mononuclear leukocytes from two sitosterolemic sisters (10). In these mononuclear cells, enhanced total binding and high affinity (receptormediated) degradation of LDL were observed and may serve to provide sterols that cannot be synthesized for cellular growth (11). In other words, low cholesterol synthesis reflected the deficiency of HMG-CoA reductase in sitosterolemic cells and was compensated for by the increased uptake of circulating plasma sterols via the receptor-mediated LDL pathway.

It is now well established that the liver is the major organ concerned with cholesterol homeostasis. Virtually all absorbed cholesterol reaches the liver by way of chylomicron remnants, and $80 \%$ of cholesterol synthesis takes place in this organ. About $75 \%$ of the circulating LDL is catabolized via receptors in the liver (12) and $100 \%$ of bile acids are produced here. The objectives of this investigation were to expand our knowledge about hepatic cholesterol metabolism in sitosterolemia. Total activity and mass of hepatic HMG-CoA reductase, the ratecontrolling enzyme for cholesterol biosynthesis, were related to $\mathrm{HMG}-\mathrm{CoA}$ reductase mRNA levels. Also, the rate $\left[{ }^{14} \mathrm{C}\right]-$ mevalonic acid was transformed to cholesterol by liver slices was measured to assess cholesterol biosynthesis beyond the formation of mevalonic acid. Hepatocyte sterol composition and structure were correlated with total and high affinity binding of LDL to liver membranes and the function of $\mathrm{HMG}$ $\mathrm{CoA}$ reductase. Our hypothesis is that diminished cholesterol synthesis is related to deficient formation of HMG-CoA reductase and is offset by the enhanced expression of tissue LDL receptors.

\section{Methods}

Clinical. Liver specimens from 12 normal subjects, aged 16-67 yr (six males and six females), were obtained from the Liver Tissue Procure- 
ment and Distribution System (National Institutes of Health contract NO1-DK-62274, University of Minnesota Hospital, Minneapolis, MN). All individuals were healthy and died unexpectedly, and their livers became available because no suitable recipient for transplantation could be found. The specimens were received on dry ice and were stored at $-70^{\circ} \mathrm{C}$ for $<3$ mo before use. Because of rapidly developing atherosclerosis, ileal bypass operations were performed in two sitosterolemic sisters (TC and $\mathrm{KiCN}$ ) aged 27 and $29 \mathrm{yr}$, respectively. Liver biopsies were obtained during surgery; a portion was submitted for morphologic evaluation and the remainder was immediately frozen and stored at $-70^{\circ} \mathrm{C}$ until used. The patients had not been under dietary or drug treatment for at least 2 mo before surgery. Informed consent was obtained from the sitosterolemic subjects, and the research protocols were approved by the human studies committees at the UMD-New Jersey Medical School, Newark, NJ and VA Medical Center, East Orange, NJ.

Determination of plasma and hepatic sterols. Duplicate samples of plasma $(1.0 \mathrm{ml})$, liver homogenate $(50-200 \mathrm{mg})$, or microsomes (2-5 $\mathrm{mg}$ ) were hydrolyzed in $25 \%$ potassium hydroxide in ethanol under reflux for $2 \mathrm{~h}$ with $30,000 \mathrm{dpm}\left[{ }^{3} \mathrm{H}\right]$ cholesterol as internal recovery standard. The sterols were extracted with hexane and converted to trimethylsilyl ether derivatives. $5 \alpha$-Cholestane was added as an internal standard and mass quantitated by capillary gas-liquid chromatography (8). The proportion of free and esterified sterols in plasma and liver were determined on separate specimens $(3,4,8)$.

Assay for hydroxymethylglutaryl coenzyme A reductase activity and relative mass. Hepatic microsomes were prepared by differential ultracentrifugation and the total protein determined as previously described (13). The assay for total HMG-CoA reductase activity was based on the methods of Shefer et al. (14) and Harwood et al. (15). Briefly, $50-200 \mu \mathrm{g}$ microsomal protein were preincubated at $37^{\circ} \mathrm{C}$ for $5 \mathrm{~min}$ in a total volume of $150 \mu \mathrm{l}$ buffer $(50 \mathrm{mM}$ Tris, $68 \mathrm{mM}$ EDTA, 5 $\mathrm{mM}$ DTT, $70 \mathrm{mM} \mathrm{KCl}, \mathrm{pH}$ 7.5) containing a NADPH generating system (34 mM NADP ${ }^{+}, 30 \mathrm{mM}$ glucose-6-phosphate, and $0.3 \mathrm{U}$ glucose-6-phosphate dehydrogenase) and 40,000 dpm [ $\left.{ }^{3} \mathrm{H}\right]$ mevalonolactone as internal recovery standard. The reaction was started with the addition of $30 \mathrm{nmol}\left[{ }^{14} \mathrm{C}\right] \mathrm{HMG}-\mathrm{CoA}$ (Amersham Corp., Arlington Heights, IL; diluted with unlabeled HMG-CoA to give a specific activity of $30 \mathrm{dpm} / \mathrm{pmol}$ ). The reaction was stopped after $10 \mathrm{~min}$ at $37^{\circ} \mathrm{C}$ with the addition of $20 \mu 16 \mathrm{~N} \mathrm{HCl}$. After lactonization of the products at $37^{\circ} \mathrm{C}$ for $30 \mathrm{~min}$, the precipitates were pelleted by centrifugation $(10,000 \mathrm{rpm}$ in a microfuge; Beckman Instruments, Palo Alto, CA) and the products in the supernatant fraction were separated by thin layer chromatography on $0.25 \mathrm{~mm}$-thick silica gel 60 plates (E. Merck, Darmstadt, FRG), developed with benzene/acetone (1:1, vol/vol), and the radioactivity determined by liquid scintillation counting. For the determination of active HMG-CoA reductase activity, the buffers for microsomal preparation and enzyme assay included a phosphatase inhibitor $(70 \mathrm{mM} \mathrm{NaF}$ replacing $\mathrm{KCl})$. The addition of purified calf intestinal or Escherichia coli alkaline phosphatases did not signifcantly increase total HMG-CoA reductase activities in sitosterolemic or control microsomes when incubated in buffer containing $\mathrm{KCl}$.

Relative mass of HMG-CoA reductase was determined by immunoblotting. $65 \mu \mathrm{g}$ of microsomal protein suspended in Lammeli sample buffer without $\beta$-mercaptoethanol were placed in a boiling water bath for $3 \mathrm{~min}$ and applied to $7.5 \%$ polyacrylamide slab gels containing $0.1 \%$ sodium dodecyl sulfate (16). The separated microsomal proteins were transferred overnight electrophoretically to Immobilin, a polyvinylidene difluoride membrane. Rabbit antirat liver HMG-CoA reductase antisera were used to detect HMG-CoA reductase protein as previously described (17), except that alkaline phosphatase conjugated goat anti-rabbit IgG was used as the second antibody and nitroblue tetrazolium and 5-bromo-4-chlor-3-indolyl phosphate produced color for detection. Both the control and sitosterolemic HMG-CoA reductase migrated at $\sim 200,000 M_{\mathrm{r}}(10)$. The relative amounts of hepatic HMG-CoA reductase present in the various samples were determined by scanning the $M_{\mathrm{r}} \simeq 200,000$ band with an LKB ultrascan XL laser densitomer (LKB Produkter, Bromma, Sweden). The relative mass of reductase enzyme protein was expressed as peak area per milligram of microsomal protein. The catalytic efficiency (pmol/peak area/min) was calculated by dividing the total enzyme activity by the relative HMG-CoA reductase enzyme protein.

Hepatic conversion of $\left[2{ }^{14} \mathrm{C}\right]$ mevalonic acid (mevalonolactone) to cholesterol. The conversion of mevalonic acid (in the stable form of mevalonolactone) to cholesterol was determined according to the method of Sabine et al. (18) as modified by Turley et al. (19). Liver slices $(50-200 \mathrm{mg}$, sliced $1 \mathrm{~mm}$ thick with a razor blade when liver was still partially frozen) were incubated in duplicate at $37^{\circ} \mathrm{C}$ for $60 \mathrm{~min}$ with $10 \mathrm{mM}\left[2-{ }^{14} \mathrm{C}\right]$ mevalonolactone (New England Nuclear, Boston, MA; diluted with unlabeled substrate to a specific activity of $4 \mathrm{dpm} /$ pmol) in $2 \mathrm{ml} \mathrm{Krebs-bicarbonate} \mathrm{buffer,} \mathrm{pH} \mathrm{7.4.} \mathrm{The} \mathrm{reaction} \mathrm{was}$ stopped with $1 \mathrm{ml} 0.2 \mathrm{~N} \mathrm{H}_{2} \mathrm{SO}_{4}$, the tissues were pelleted at $2,000 \mathrm{~g}$ for $5 \mathrm{~min}$, and the pellets were hydrolyzed in $25 \% \mathrm{KOH} / 50 \%$ ethanol under reflux for $2 \mathrm{~h}$ with $30,000 \mathrm{dpm}\left[{ }^{3} \mathrm{H}\right]$ cholesterol for recovery standard. The labeled cholesterol was separated on alumina columns (20) and counted by liquid scintillation spectroscopy.

Binding of low density lipoproteins to liver membranes. LDL (1.019 $<d<1.063$ ) was isolated from plasma from normal volunteers and from the sitosterolemic patients by differential centrifugation (21) and labeled with [ ${ }^{125}$ I] (New England Nuclear) by the monohydrochloride method (22). Binding of LDL to liver membranes was assayed according to the methods by Kovanen et al. $(23,24)$ and Harder-Spengel et al. (25). Liver membranes were resuspended in buffer $\mathrm{A}(100 \mathrm{mM} \mathrm{NaCl}$, $0.5 \mathrm{mM} \mathrm{CaCl}_{2}$, and $20 \mathrm{mM}$ Tris, $\mathrm{pH} 7.4$ ) at a protein concentration of $3-5 \mathrm{mg} / \mathrm{ml}$. Duplicate aliquots of liver membranes $(50-100 \mu \mathrm{g}$ protein) were incubated in Ultraclear centrifuge tubes $(0.8 \mathrm{ml}$ size; Beckman Instruments) in an ice bath in a total volume of $80 \mu \mathrm{l}$ buffer B (buffer A supplemented with $20 \mathrm{mg} / \mathrm{ml}$ serum bovine albumin) containing 25 $\mu \mathrm{g} / \mathrm{ml}{ }^{125} \mathrm{I}-\mathrm{LDL}$. A pool of LDL from normal plasma was used for control liver membranes, whereas liver membranes from the sitosterolemic patients were incubated with their own LDL. After $60 \mathrm{~min}$, the incubation mixtures were underlayered with $150 \mu \mathrm{l}$ fetal bovine serum (Gibco Laboratories, Grand Island, NY) and centrifuged at $100,000 \mathrm{~g}$ for $30 \mathrm{~min}$. The pellets were washed with $200 \mu \mathrm{l}$ fetal bovine serum and the radioactivity in the pellets was counted in a gamma counter with a correction for counts of blank samples in which liver membranes were replaced with assay buffer. High affinity (receptor-mediated) binding was determined as the difference between total binding (assayed in the absence of unlabeled LDL) and non-specific binding (assayed in the presence of 40-fold excess unlabeled LDL).

RNA isolation and northern blotting analysis. RNA was prepared from frozen human liver samples $(0.1-0.5 \mathrm{~g})$ by a recently described, low temperature modification (26) of the guanidinium thiocyanate extraction procedure (27). The frozen liver pieces were placed in $20 \mathrm{ml}$ of ice-cold $5 \mathrm{M}$ guanidinium thiocyanate containing $5 \% \beta$-mercaptoethanol and quickly disruptęd with a Polytron PCU-2-110 homogenizer (Polysciences Inc., Warrington, PA). After four extractions with guanidine hydrochloride followed by ethanol precipitation, the RNA was taken up in sterile, diethyl pyrocarbonate-treated water. Poly $\mathrm{A}^{+}$ RNA was isolated by fractionation on oligo (dT) cellulose chromatography (28). The quantity of poly A+ RNA was determined spectrophotometrically. The RNA was electrophoresed on $1 \%$ agarose gels containing formaldehyde and transferred to Gene Screen Plus membranes. The membranes were probed with ${ }^{32}$ P-labeled pHRED 102 and pRED 227 for HMG-CoA reductase and pCAT10 for catalase. These cDNA probes for HMG-CoA reductase and catalase were purchased from American Type Culture Collection (Rockville, MD). Labeling of the probes and hybridization were carried out as previously described (29). The relative levels of mRNA were determined by densitometric scanning using catalase as an internal control.

Light microscopy. Pathologic changes in the liver biopsy were assessed by light microscopic examination of buffered-formalin-fixed and paraffin-embedded $6 \mu$ m-thick sections stained with hematoxylin 
and eosin. Special stains for reticulum (Verhoeff's), collagen (Mason's), and iron (Perl's) were also utilized.

Electron microscopy. Portions of the liver biopsies were sliced into small pieces that were immediately fixed in ice-cold $s$-collidine-buffered osmium tetroxide at $\mathrm{pH}$ 7.3. After dehydration in a series of graded methanol solutions followed by propylene oxide, the specimens were embedded in Epon 812. Plastic-embedded $0.5 \mu \mathrm{m}$-thick sections, stained with toluidine blue, were first examined in the light microscope to delineate the areas to be further evaluated at the ultrastructural level. Ultrathin sections stained with uranyl acetate and lead citrate were then examined with Zeiss EM-10C electron microscope.

Statistical analyses. Data were analyzed statistically by comparing the patients' values with the 95 and $99 \%$ confidence intervals for the control group as described by Gardiner and Altman (30). The major assumption that underlies this calculation is that the measurements for sterol concentration, HMG-CoA reductase activity, HMG-CoA reductase protein, mevalonic acid incorporation into cholesterol, and total and receptor-mediated LDL binding from the control livers fit a normal distribution. From these values the mean and 95 and $99 \%$ confidence intervals were calculated (30) and compared with the results for the sitosterolemic individuals. Values lying outside the 95 and 99\% confidence intervals, respectively, have an increasing probability of arising from a different distribution than the controls.

\section{Results}

In Table I are presented measurements of plasma sterol concentrations and composition in 12 control and two sitosterolemic subjects. Total plasma sterol concentrations are increased in the two sitosterolemic sisters because of the abundance of plant sterols and $5 \alpha$-stanols that amounted to $\sim 17 \%$ of the total sterol pool compared with only trace amounts in the control subjects. About $75 \%$ of the cholesterol and $70 \%$ of the plant sterols were esterified.

Table II contains measurements of sterols in whole liver and microsomal specimens from one sitosterolemic and 12 control subjects. The control specimens came from transplant donors where no suitable recipient was available. Cholesterol concentrations were $24 \%$ lower in whole liver and $14 \%$ less in microsomes from the sitosterolemic subject (TC) compared with the mean for the controls. The whole liver cholesterol concentration from the sitosterolemic subject fell outside the $95 \%$ confidence interval for the control mean. The deficiency

Table I. Plasma Sterol and 5 $\alpha$-Stanol Concentrations

\begin{tabular}{lcc}
\hline & \multicolumn{2}{c}{ Mean \pm SEM } \\
\cline { 2 - 3 } Subjects & Cholesterol & Plant sterols $+5 \alpha$-stanols* \\
\hline & $m g / d l$ & $m g / d l(\%$ of total) \\
$\begin{array}{c}\text { Control } \\
n=12\end{array}$ & & \\
$\begin{array}{c}\text { Sitosterolemia } \\
\text { KiCN }(5)^{\ddagger}\end{array}$ & $189 \pm 17$ & $0.44 \pm 0.16(0.4)$ \\
$\operatorname{TC}(5)^{\ddagger}$ & $217 \pm 15$ & \\
& $235 \pm 17$ & $43.2 \pm 1.3(16.6)$ \\
& & $48.0 \pm 1.2(17)$
\end{tabular}

* Plant sterols (campesterol, 27\%; stigmasterol, 5\%; sitosterol, 48\%; and avenosterol, $4 \%$ ) and $5 \alpha$-stanols (cholestanol, $2 \% ; 5 \alpha$-campestanol, $5 \%$; and $5 \alpha$-sitostanol, $9 \%$ ) were present in the plasma of sitosterolemic subjects, but only traces of cholestanol and sitosterol were detected in control plasma.

${ }^{\ddagger}$ Number of weekly specimens analyzed.
Table II. Sterols and 5a-Stanols in Whole Liver and Microsomes from Normal and Sitosterolemic Subjects

\begin{tabular}{|c|c|c|c|c|}
\hline \multirow[b]{3}{*}{ Subjects } & \multirow{2}{*}{\multicolumn{2}{|c|}{ Whole liver }} & \multicolumn{2}{|c|}{ Microsomes } \\
\hline & & & & \\
\hline & Cholesterol & $\begin{array}{l}\text { Plant sterols and } \\
5 \alpha \text {-stanols }\end{array}$ & Cholesterol & $\begin{array}{c}\text { sterols and } \\
5 \alpha \text {-stanols }\end{array}$ \\
\hline & \multicolumn{2}{|c|}{$\mu \mathrm{mol} / \mathrm{g}$ liver (\% total) } & \multicolumn{2}{|c|}{$\begin{array}{l}\text { nmol/mg protein } \\
(\% \text { total })\end{array}$} \\
\hline \multicolumn{5}{|l|}{ Control $^{\ddagger}$} \\
\hline$n=12$ & $5.64 \pm 0.67^{\S}$ & $0.05 \pm 0.05(0.9)$ & $53.0 \pm 3.8$ & trace \\
\hline \multicolumn{5}{|c|}{ Sitosterolemia } \\
\hline TC & 4.17 & $0.78(18.3)^{*}$ & 45.6 & $12.2(18)$ \\
\hline
\end{tabular}

* Composed of campesterol (24\%), stigmasterol (4\%), sitosterol (50\%), avenosterol (4\%), cholestanol (4\%), $5 \alpha$-campestanol (4\%), and $5 \alpha$-sitostanol (10\%).

${ }^{\ddagger}$ Mean \pm SEM

$\S 95 \%$ confidence interval for control mean: 4.24-7.11 $\mu \mathrm{mol} / \mathrm{g}$ liver.

of cholesterol was partially offset by the substantial content of plant sterols and $5 \alpha$-stanols that amounted to $18 \%$ of the total sterol pool and were deposited in about the same proportions as found in plasma (Table I). Control liver and microsomes contained only trace amounts of plant sterols and $5 \alpha$-stanols. In contrast to plasma, $90 \%$ of the cholesterol and plant sterols was unesterified in both whole liver and microsomal fractions.

Histology was evaluated in liver specimens from both sitosterolemic subjects. Light microscopy showed normal appearing architecture without fibrosis (Fig. $1 \mathrm{~A}$ ). Golden-brown (lipofuscin-like) granules were deposited randomly in most hepatocytes (Fig. $1 B$ ).

Electron microscopic examination revealed dominant deposition of electron dense pigment accumulating in the vicinity of the bile canaliculi (Fig. 2). These deposits appear to correspond to the golden-brown granules noted by light microscopy (Fig. $1 B$ ). The Golgi cisterns looked markedly dilated and the Golgi vesicles were loaded with the electrondense material. The rough endoplasmic reticulum profiles appeared somewhat dilated and lost some of their ribosomes.

In Table III are presented determinations of hepatic microsomal HMG-CoA reductase activity from 11 control and two sitosterolemic liver specimens. Microsomes were prepared and assayed in the presence and absence of the phosphatase inhibitor, sodium fluoride, so that total enzyme activity and proportion of active HMG-CoA reductase were determined for each specimen. In the control liver microsomes, mean total HMGCoA reductase activity was 5.3 and 8.2 times greater, respectively, than the values from the two sitosterolemic liver microsomal specimens, both of which were outside the $95 \%$ confidence interval for the control mean. Furthermore, only $49 \%$ of the total activity was expressed in the control liver microsomes compared with $72 \%$ active HMG-CoA reductase in a sitosterolemic specimen. Thus, total hepatic microsomal HMG-CoA reductase activity is markedly depressed in sitosterolemia, but a greater proportion of the enzyme is active than in control specimens.

Table IV contains the values for relative HMG-CoA reductase protein concentrations that were determined by immunoblotting using rabbit anti-rat liver HMG-CoA reductase 

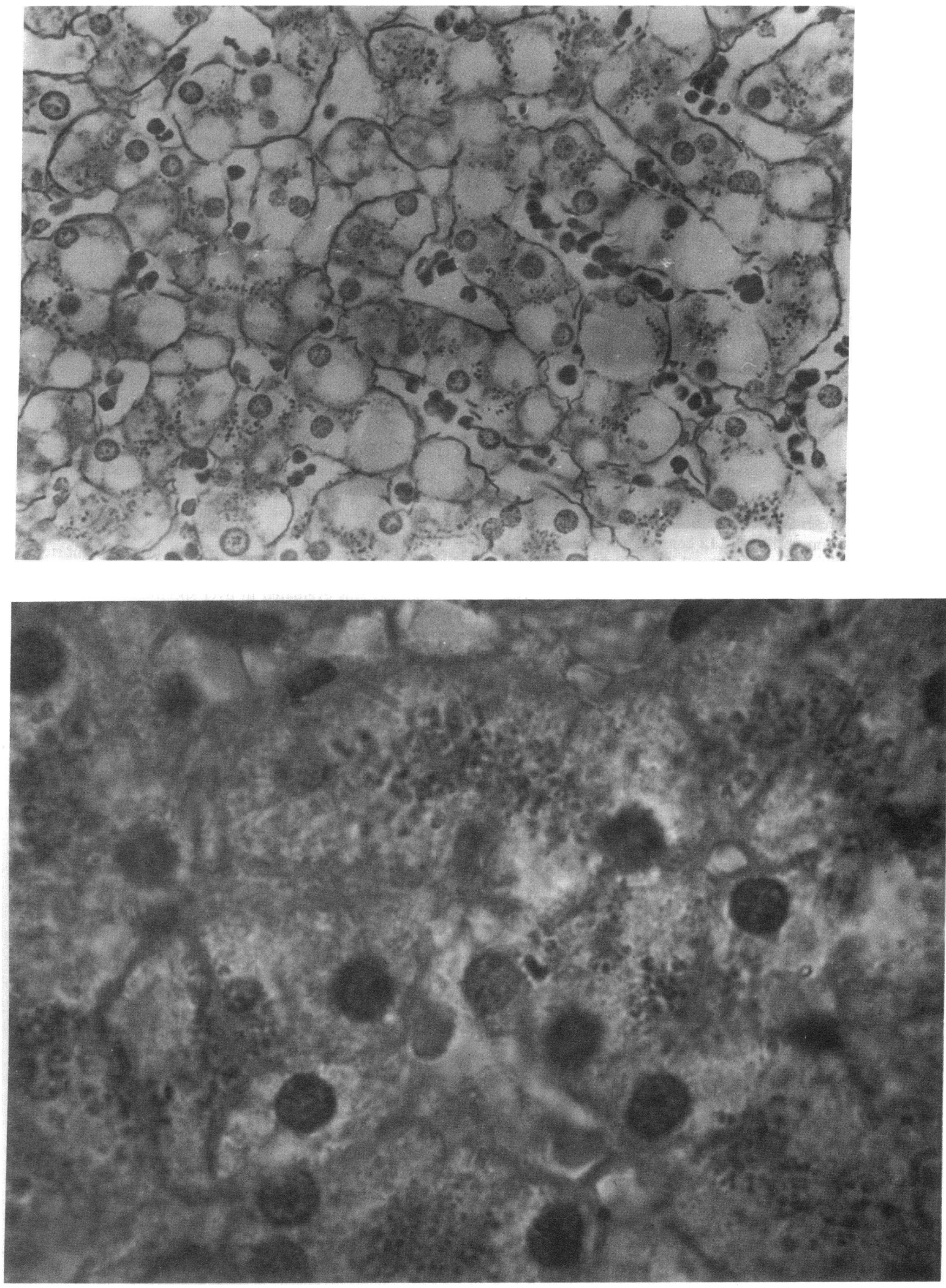

Figure 1. Light microscopy of liver from sitosterolemic subject. $(A)$ Normal reticulum framework without fibrosis. Verhoeff's stain. $\times 250$. $(B)$ Golden-brown lipofuscin-like granules were deposited randomly in hepatocytes. Hematoxylin and eosin. $\times 250$. 


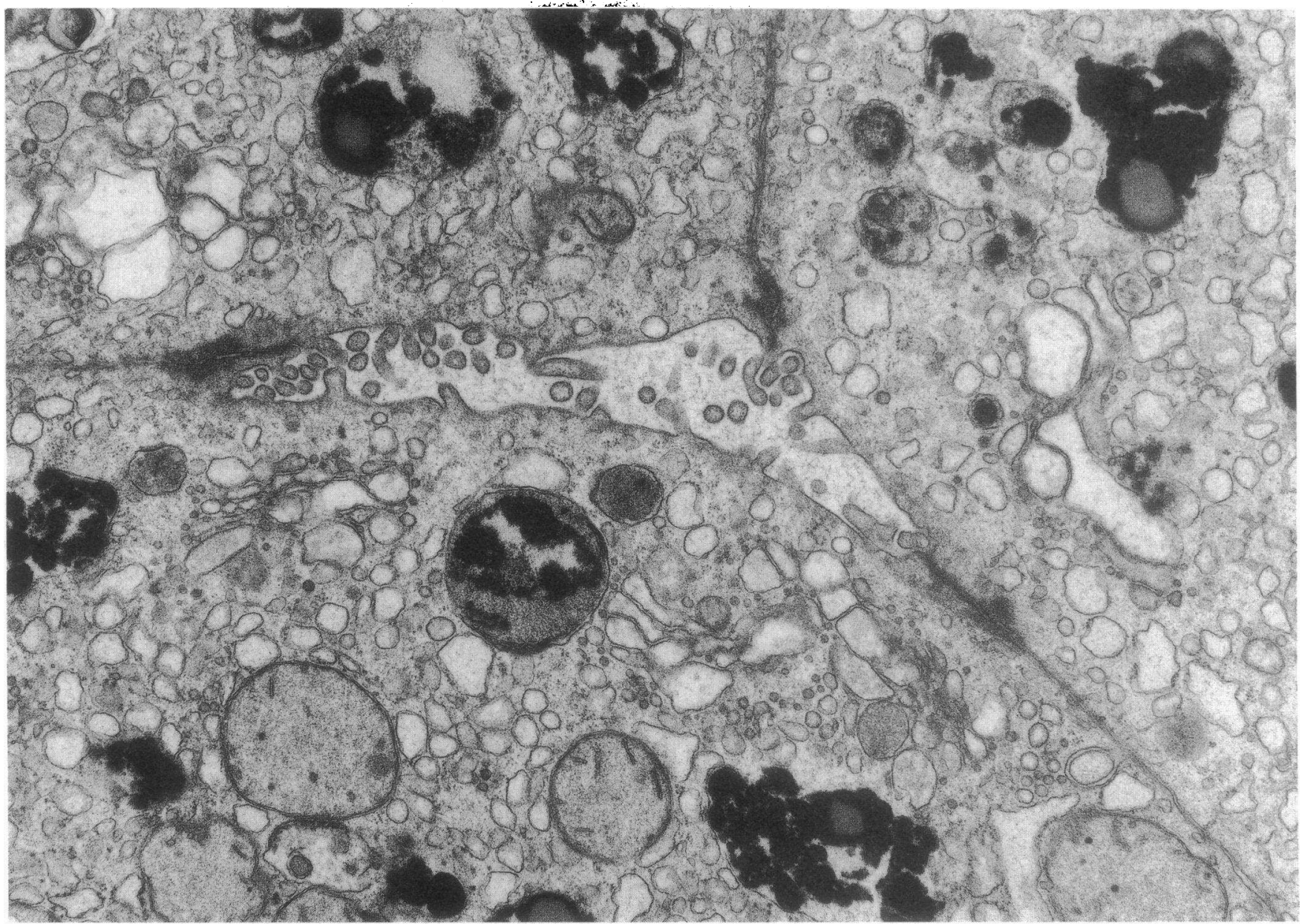

Figure 2. Electron microscopy of liver from sitosterolemic subject. Normal bile canaliculus, surrounded by electron-dense material and dilated Golgi vesicles. The rough endoplasmic reticulum appeared dilated. $\times 5,000$.

antisera and quantitated by densitometric scanning. The 11 control and 2 sitosterolemic liver microsomal preparations were the same as assayed for total and percent active HMG-

Table III. Hydroxymethylglutaryl Coenzyme A Reductase Activity in Hepatic Microsomes from Normal and Sitosterolemic Subjects

\begin{tabular}{ccc}
\hline & \multicolumn{2}{c}{ HMG-CoA reductase activity* } \\
\cline { 2 - 3 } Subjects & \multicolumn{1}{c}{ Total } \\
\hline & pmol/mg per min & \% active \\
Control & & \\
$n=11$ & $98.1 \pm 28.8^{\ddagger}$ & $49.1 \pm 14.0$ \\
Sitosterolemia & & \\
TC & 18.4 & 72 \\
KiCN & 11.9 & NA $^{\S}$ \\
\hline
\end{tabular}

* Total and expressed activities were measured with microsomes prepared and assayed in the absence and presence of $70 \mathrm{mM} \mathrm{NaF}$. Control values are mean \pm SEM. Patients' values are averages for two determinations.

¥ 95\% confidence interval for control mean: $27.6-168.6 \mathrm{pmol} / \mathrm{mg}$ per $\min$

${ }^{\S} \mathrm{NA}$, not available.
CoA reductase activity (Table III). The Western blots of HMG-CoA reductase are shown in Fig. 3 and illustrate the severe depletion of enzyme protein in the two sitosterolemic liver microsomal preparations as compared with 11 controls. Densitometric scans (Table IV) show that the mean relative mass of HMG-CoA reductase per milligram of microsomal protein from the 11 control liver specimens was 6.8 and 8.9 times larger, respectively, than the values for the two sitosterolemic liver microsomal specimens which fall substantially outside the $99 \%$ confidence interval for the control mean. Thus, markedly reduced microsomal HMG-CoA reductase activity results from a severe deficiency of enzyme protein in the sitosterolemic livers. The catalytic efficiencies of the enzyme, calculated by dividing the total HMG-CoA reductase activity (Table III) by the relative enzyme protein mass (Table IV), are quite similar in the control and sitosterolemic liver specimens and suggest that the enzyme produced by the sitosterolemic livers is normal with respect to catalytic function. However, the expressed catalytic efficiency of HMG-CoA reductase determined by multiplying the total catalytic efficiency by the percent active enzyme was $64 \%$ higher in sitosterolemic liver microsomes from patient TC than the mean value for the control specimens. Thus, to compensate for decreased cholesterol synthesis and deficient enzyme protein, more microsomal HMG-CoA reductase is catalytically active in sitosterolemic liver microsomes. 
Table IV. Hepatic Microsomal HMG-CoA Reductase

Concentrations from Control and Sitosterolemic Subjects

\begin{tabular}{cccc}
\hline & $\begin{array}{c}\text { Relative HMG-CoA } \\
\text { Reductase } \\
\text { Concentration }\end{array}$ & \multicolumn{2}{c}{ Catalytic* efficiency } \\
\cline { 3 - 4 } & $\begin{array}{c}\text { Total } \\
\text { peak area/mg } \\
\text { microsomal protein }\end{array}$ & pmol/peak area per min \\
Control & $1.43 \pm 0.14^{\ddagger}$ & 68.6 & 33.4 \\
$n=11$ & 0.21 & & \\
$\begin{array}{c}\text { Sitosterolemia } \\
\text { TC }\end{array}$ & 0.16 & 76.2 & 54.9 \\
KiCN & & 74.3 & NA $^{\S}$ \\
\hline
\end{tabular}

* Total catalytic efficiency, total enzyme activity/relative enzyme concentration. Expressed catalytic efficiency, $\%$ active $\times$ total catalytic efficiency.

${ }^{\ddagger}$ Mean \pm SEM, $99 \%$ confidence interval: $0.97-1.89$ peak area/mg microsomal protein.

${ }^{\S}$ Not available.

To explain the severe deficiency of HMG-CoA reductase (protein mass and enzyme activity), RNA was isolated from liver specimens obtained from two control and one sitosterolemic subjects and hybridized with pRED 227 and pHRED 102 , which are full length cDNA probes for hamster and human HMG-CoA reductase, respectively, and pCAT 10, a probe for human catalase mRNA. The Northern blots of the hybridized sitosterolemic and control liver RNA are presented in Fig. 4. Virtually no signals were detected from sitosterolemic mRNA for HMG-CoA reductase probed with either pRED 227 or pHRED 102, as contrasted with the signals from the probed mRNA in the control specimens. All three specimens gave signals for catalase mRNA that indicated that the mRNA isolated from the sitosterolemic and control livers were intact. Thus, the deficiency of hepatic microsomal HMG-CoA reductase protein in sitosterolemic liver could be related to the low levels of HMG-CoA reductase mRNA that are available for translation.

To obtain information on cholesterol synthesis beyond HMG-CoA reductase, the conversion of $\left[2-{ }^{14} \mathrm{C}\right] \mathrm{mevalonic}$ acid to cholesterol was investigated in liver slices from 12 control individuals and sitosterolemic subject TC. The results are presented in Table $\mathrm{V}$. The rate of cholesterol biosynthesis from mevalonic acid was $50 \%$ lower in the sitosterolemic liver as compared with the mean for the 12 control liver slices and was outside the $99 \%$ confidence interval for the control mean. Thus, cholesterol synthesis after the formation of mevalonic acid is depressed in sitosterolemic liver and may reflect the deficiency of other enzymes in the pathway from mevalonic acid to cholesterol.
Total and high affinity binding of ${ }^{125} \mathrm{I}-\mathrm{LDL}$ to liver membranes was measured in 12 control and two sitoterolemic preparations (Table VI). In a preliminary experiment, optimal conditions for the assay were defined in control liver membranes: high affinity (receptor-mediated) binding was linear over a 60-min incubation period with up to $100 \mu \mathrm{g}$ of liver membranes and $50 \mu \mathrm{g} / \mathrm{ml}$ of ${ }^{125} \mathrm{I}-\mathrm{LDL}$. All subsequent assays were performed with a substrate concentration of $25 \mu \mathrm{g} / \mathrm{ml}$ and optimal conditions. Total binding (assayed in the absence of unlabeled LDL) was 54 and $80 \%$ higher, respectively, in the two sitosterolemic liver membrane specimens than the mean for the control measurements, and both values were beyond the $99 \%$ confidence interval for the control (Table VI). Similarly, high affinity (receptor mediated) LDL binding, reported as the difference between total binding and nonspecific binding, was 2.2 and 3.3 times greater, respectively, in the sitosterolemic than the control livers, and exceeded the $99 \%$ confidence interval for the control as well. Therefore, a much higher proportion of LDL was receptor bound and much more circulating LDL was taken up by sitosterolemic than control liver membranes because of the expression of additional LDL receptors.

\section{Discussion}

These results demonstrate markedly reduced HMG-CoA reductase activity and enzyme protein, which was catalytically normal in liver microsomes isolated from two sitosterolemic subjects, compared with the mean value for microsomes from 11 control liver specimens. Thus, extremely low enzyme activity in sitosterolemic liver is caused by a severe deficiency of HMG-CoA reductase protein and not an altered state of enzyme activation. This enzyme which catalyzes the conversion of hydroxymethylglutaryl coenzyme A to mevalonic acid is considered rate limiting for cholesterol biosynthesis. With the exception of small amounts utilized for ubiquinone or dolichol synthesis, virtually all the mevalonic acid is committed for cholesterol biosynthesis and thus the regulation of cholesterol biosynthesis is modulated by the availability of mevalonic acid.

In the case of the two sitosterolemic subjects, their hepatic microsomal HMG-CoA reductase reacted similarly immunologically and exhibited about the same catalytic efficiency as the enzyme present in the control liver microsomes. Each unit of enzyme protein from sitosterolemic and control livers was able to catalyze HMG-CoA to mevalonic acid equivalently. However, because of the severe deficiency of HMG-CoA reductase protein, much less mevalonic acid was formed despite the fact that a greater proportion of the microsomal enzyme was active in sitosterolemic as compared with control livers ( 72 vs. $49 \%$ ). A similar deficiency of HMG-CoA reductase

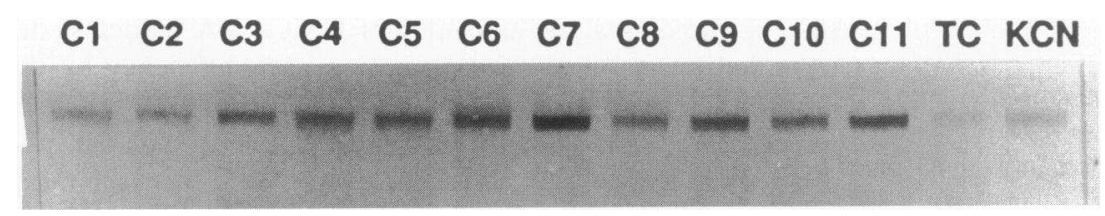

Figure 3. Western blot of human liver microsomal HMG-CoA reductase. Microsomal proteins (65 $\mu \mathrm{g}$ per lane) from 11 control and two sitosterolemic livers were separated on a $7.5 \%$ polyacrylamide gel that contained $0.1 \%$ sodium dodecyl sulfate without $\beta$-mercaptoethanol. Proteins were transferred electrophoretically to immobilin and HMG-CoA reductase was detected with rabbit antirat liver HMG-CoA reductase sera. The 200-kD band which corresponds to HMG-CoA reductase is shown and illustrates the severe deficiency of enzyme protein in the two sitosterolemic specimens ( $T C$ and $K i C N$ ) as compared with the 11 controls. 


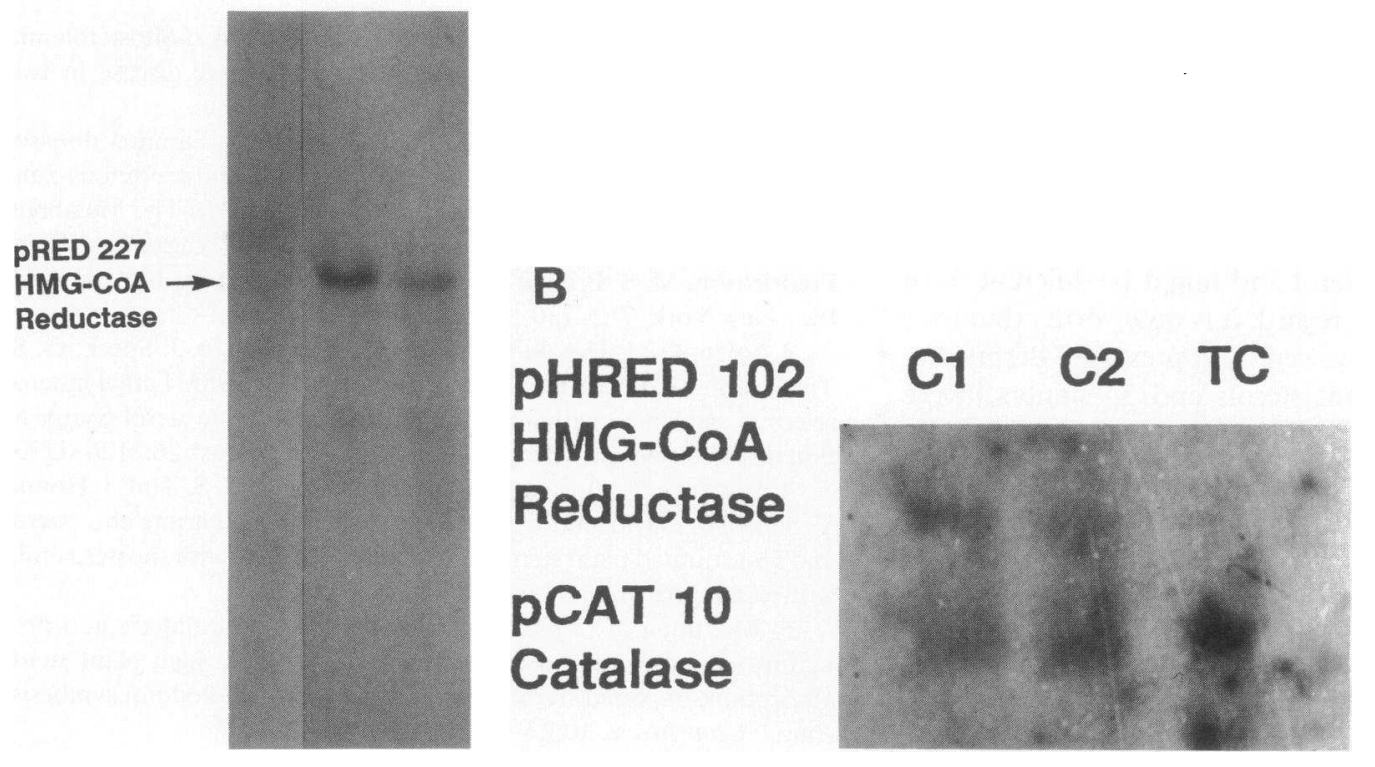

Figure 4. Northern blot analysis of sitosterolemic mRNA. Northern blots of liver poly $\mathrm{A}^{+}$RNA from a sitosterolemic $(T C)$ and two control subjects that were probed with pRED 227 in $A$ and pH RED 102 and pCAT 10 in $B$.

activity and enzyme protein was demonstrated recently in freshly isolated mononuclear leukocytes from these sitosterolemic subjects (10).

The severe depletion of HMG-CoA reductase protein can be accounted for by the absence of mRNA which codes for enzyme synthesis. When the RNA pool isolated from liver was hybridized with ${ }^{32} \mathrm{P}$-labeled pRED 227 or pHRED 102, which are full sequence hamster and human HMG-CoA reductase cDNA probes, virtually no signal from sitosterolemic mRNA was detected by Northern blot analysis. In contrast, HMGCoA reductase mRNA from control subjects was seen when hybridized with the two probes. Both the sitosterolemic and control specimens showed mRNA for human catalase, a ubiquitous liver enzyme when probed with pCAT 10. Thus, the absent signal from the hybridized sitosterolemic specimens reflected a deficiency of mRNA for HMG-CoA reductase rather than deteriorated mRNA and is consistent with diminished synthesis of enzyme protein (Table IV).

The possibility that other enzymes of the cholesterol biosynthetic pathway that are coordinately regulated with HMGCoA reductase are deficient, is suggested by the finding of a $50 \%$ decrease in incorporation of $\left[{ }^{14} \mathrm{C}\right]$ mevalonic acid into

Table V. Hepatic Cholesterol Biosynthesis from $\left[{ }^{14} \mathrm{C}\right]$ Mevalonic Acid

\begin{tabular}{cc}
\hline Subjects & Cholesterol biosynthesis* \\
& $p m o l / g$ liver per $h$ \\
Control & \\
$n=12$ & $224 \pm 32^{\ddagger}$ \\
Sitosterolemia & \\
TC & 112
\end{tabular}

\footnotetext{
* Values shown are mean \pm SEM for the control group and average of two determinations for the patient.

$\$ 99 \%$ confidence interval for the control mean: $124.4-323.0 \mathrm{pmol} / \mathrm{g}$ liver per $h$.
}

cholesterol (Table V). This decreased conversion is unlikely to be caused by dilution of labeled substrate because mevalonate synthesis is actually markedly decreased in the sitosterolemic livers. In fact, because of reduced formation, the rate of mevalonic acid conversion to cholesterol may be overestimated in the sitosterolemic liver slices. The key abnormality may lie in a gene that coordinates the synthesis of several enzymes in the cholesterol biosynthetic pathway (31).

Sitosterolemic liver cells respond to reduced cholesterol synthesis by increasing the total and high affinity (receptor mediated) binding of circulating LDL to hepatocyte membranes (Table VI). Similarly, in other experiments the in vivo catabolism of intravenously injected ${ }^{125} \mathrm{I}$-LDL was increased $60 \%$ in a sitosterolemic as compared with three matched control subjects studied by Biel et al. (32). Both lines of evidence indicate that more LDL receptors are expressed by sitosterol-

Table VI. Receptor-Mediated Low-Density Lipoprotein Binding to Liver Membranes

\begin{tabular}{lcc} 
& \multicolumn{2}{c}{ Low density lipoprotein binding* } \\
\cline { 2 - 3 } Subjects & Total & Receptor-mediated \\
\hline & $n g /$ mg protein & $n g / m g$ protein $(\%$ total) \\
Control & & \\
$n=12$ & $204.0 \pm 10.0^{\ddagger}$ & $95.4 \pm 8.2(47 \pm 4)^{\S}$ \\
Sitosterolemia & & \\
TC & 315.3 & $193.2(61)$ \\
KiCN & 336.8 & $312.8(85)$ \\
\hline
\end{tabular}

* High affinity (receptor-mediated) binding was determined as the difference between total binding (assayed in the absence of unlabeled LDL) and nonspecific binding (assayed in the presence of 40-fold excess unlabeled $L D L)$. Values shown are mean \pm SEM. Patients values are average of two determinations.

$\$ 99 \%$ confidence interval for control mean: $173.0-235.2 \mathrm{ng} / \mathrm{mg}$ protein.

$\S 99 \%$ confidence interval for control mean: $69.9-120.9 \mathrm{ng} / \mathrm{mg}$ protein. 
emic hepatocytes. Consequently, the failure to synthesize cholesterol leads to the dependence on circulating LDL as the source for cellular sterols. That this might be so was indicated by the similar proportions of plant sterols and $5 \alpha$-stanols that were present in plasma and liver cells from the sitosterolemic subjects (Tables I and II). If more de novo cholesterol synthesis took place in the liver, the proportion of plant sterols and $5 \alpha$-stanols in tissue and subcellular fractions would be diluted by newly synthesized cholesterol and might be different from that found in plasma. In this regard, it is noteworthy that liver architecture and cell structure were well preserved despite the presence of almost $18 \%$ plant sterols and $5 \alpha$-stanols in the tissue sterol pool. However, golden-brown to brown granules that might represent lipofuscin pigment were detected by both light and electron microscopy in sitosterolemic liver cells (Figs. $1 B$ and 2). Although the nature of this pigment is not known, it is tempting to suggest that it represents a fragment of the LDL that is cleared to provide cellular sterols.

It is also important to note that hepatic tissue and microsomes from a sitosterolemic subject contained 24 and $14 \%$ less cholesterol, respectively, than control livers. Therefore, it is not likely that depressed HMG-CoA reductase activity, enzyme protein, and mRNA resulted from feedback suppression by cellular cholesterol. Further, Boberg, Åkerland, and Björkhem have convincingly demonstrated that rats made sitosterolemic with intravenous infusions of sitosterol have increased rather than suppressed hepatic HMG-CoA reductase activity (33). Thus, sitosterol is a poor feedback inhibitor of cholesterol biosynthesis, a finding also observed in human fibroblasts by Goldstein and Brown (34). In most cells, the regulation of HMG-CoA reductase is coordinated with the expression of LDL receptors so that both functions respond to the same stimuli and change in the same direction. In contrast, this relationship was lost in both sitosterolemic liver and mononuclear cells (10). The upregulation of LDL receptors in sitosterolemic liver (Table VI) also argues against possible feedback suppression of cholesterol synthesis by the cellular and plasma sterol pools. In support, we have recently reported that bile acid malabsorption produced by ileal bypass surgery or bile acid binding resins failed to increase cholesterol synthesis or HMG-CoA reductase activity in freshly isolated mononuclear cells from these two sitosterolemic subjects although plasma cholesterol levels declined substantially (35). Taken together, these findings buttress our contention that low cholesterol biosynthesis (reduced HMG-CoA reductase) is an inherited abnormality in sitosterolemia.

In summary, hepatic cholesterol biosynthesis in sitosterolemia is severely depressed. Microsomal HMG-CoA reductase, the enzyme that catalyzes the rate-limiting reaction in the pathway, is markedly decreased owing to low levels of mRNA to translate for synthesis. Enhanced total and receptor-mediated uptake of LDL compensate to provide cellular sterols that cannot be synthesized.

\section{Acknowledgments}

The expert technical assistance of Susan Hauser, Susan Lerner, Bibiana Pcolinsky, Eva Paroulek, Nina Kovell, and Barbara Rouse is gratefully acknowledged.

This investigation was supported by grants from the U.S. Public Health Service: HL-17818, HL-18094, DK-18707, DK-26756 and the Research Service, Veterans Administration.

\section{References}

1. Bhattacharyya, A. K., and W. E. Connor. 1974. $\beta$-Sitosterolemia and xanthomatosis. A newly described lipid storage disease in two sisters. J. Clin. Invest. 53:1033-1043.

2. Salen, G., S. Shefer, and V. Berginer. 1983. Familial diseases with storage of sterols other than cholesterol: cerebrotendinous xanthomatosis and sitosterolemia with xanthomatosis. In The Metabolic Basis of Inherited Disease. J. B. Stanbury, J. B. Wyngaarden, D. S. Fredrickson, M. S. Brown, and J. L. Goldstein, editors. McGraw-Hill Inc., New York. 712-730.

3. Salen, G., I. Horak, M. Rothkopf, J. B. Cohen, J. Speck, G. S. Tint, V. Shore, B. Dayal, T. Chen, and S. Shefer. 1985. Lethal atherosclerosis associated with abnormal plasma and tissue sterol composition in sitosterolemia with xanthomatosis. J. Lipid Res. 26:1126-1133.

4. Salen, G., P. O. Kwiterovich, Jr., S. Shefer, G. S. Tint, I. Horak, V. Shore, B. Dayal, and E. Horak. 1985. Increased plasma cholesterol and $5 \alpha$-saturated plant sterol derivatives in subjects with sitosterolemia with xanthomatosis. J. Lipid Res. 26:203-209.

5. Miettinen, T. 1980. Phytosterolemia, xanthomatosis and premature atherosclerotic arterial disease: a case with high plant sterol absorption, impaired sterol elimination and low cholesterol synthesis. Eur. J. Clin. Invest. 10:27-35.

6. Shulman, R. S., A. K. Bhattacharyya, W. E. Connor, and D. S Fredrickson. 1976. $\beta$-Sitosterolemia and xanthomatosis. $N$. Engl. J. Med. 294:481-482.

7. Gregg, R., W. E. Connor, D. S. Lin, and H. B. Brewer, Jr. 1986. Abnormal metabolism of shellfish sterols in a patient with sitosterolemia and xanthomatosis. J. Clin. Invest. 77:1864-1872.

8. Salen, G., V. Shore, G. S. Tint, T. Forte, S. Shefer, I. Horak, E. Horak, B. Dayal, L. Nguyen, A. K. Batta, F. T. Lindgren, and P. O. Kwiterovich, Jr. 1989. Increased sitosterol absorption, decreased removal and expanded body pools compensate for reduced cholesterol synthesis in sitosterolemia with xanthomatosis. J. Lipid Res. 30:1319-1330.

9. Lin, H.-J., C. Wang, G. Salen, K.-C. Lam, and T. K. Chan. 1983. Sitosterol and cholesterol metabolism in a patient with coexisting phytosterolemia and cholestanolemia. Metab. Clin. Exp. 32:126-133.

10. Nguyen, L., G. Salen, S. Shefer, G. S. Tint, V. Shore, and G. Ness. 1990. Decreased cholesterol biosynthesis in sitosterolemia with xanthomatosis: diminished mononuclear leukocyte 3-hydroxy-3methylglutaryl coenzyme A reductase activity and enzyme protein associated with increased low density lipoprotein receptor function. Metab. Clin. Exp. 39:436-443.

11. Nguyen, L., S. Shefer, G. Salen, I. Horak, G. S. Tint, and D. J. McNamara. 1988. The effect of abnormal plasma and cellular sterol content and composition on low density lipoprotein uptake and degradation by monocytes and lymphocytes in sitosterolemia with xanthomatosis. Metab. Clin. Exp. 37:346-351.

12. Spady, D. K., D. W. Bilheimer, and J. M. Dietschy. 1983. Rates of receptor-dependent and independent low density lipoprotein uptake in the hamster. Proc. Natl. Acad. Sci. USA. 80:3499-3503.

13. Shefer, S., G. Salen, and A. K. Batta. 1986. Methods of assay. In Cholesterol $7 \alpha$-Hydroxylase ( $7 \alpha$-Monoxygenase). R. Fears and J. R. Sabine, editors. CRC Press Inc., Boca Raton, FL. 43-49.

14. Shefer, S., S. Hauser, V. Lapar, and E. H. Mosbach. 1973. Regulatory effects of sterols and bile acids on hepatic 3-hydroxy-3methylglutaryl-CoA reductase and cholesterol $7 \alpha$-hydroxylase in the rat. J. Lipid Res. 14:573-580.

15. Harwood, H. J., Jr., M. Schneider, and P. W. Stacpoole. 1984. Regulation of human leukocyte microsomal hydroxymethylglutarylCoA reductase mechanism. Biochim. Biophys. Acta. 805:245-251.

16. Lammeli, U. K. 1970. Cleavage of structural proteins during the assembly of the head of bacteriophage T4. Nature (Lond.). 227:680-685.

17. Ness, G. C., M. J. McCreery, C. E. Sample, M. Smith, and L. C. Pendleton. 1985. Sulfhydryl/disulfide forms of rat liver 3-hydroxy-3methylglutaryl coenzyme A reductase. J. Biol. Chem. 260:1639516399. 
18. Sabine, J. R., S. Abraham, and I. L. Chaikoff. 1967. Control of lipid metabolism in hepatoma BW 7756 to fasting and to feedback control. Cancer Res. 27:793-799.

19. Turley, S. D., C. E. West, and B. J. Horton. 1976. Sterol synthesis in the liver, intestine, and lung of the guinea pig. Lipids. 11:281286.

20. McNamara, D. J., C. A. Botha, and D. Mendelson. 1985. Sterol synthesis in vitro in freshly isolated mononuclear leukocytes from familial hypercholesterolemic patients treated with probucol. Biochim. Biophys. Acta. 833:412-416.

21. Havel, R. J., H. A. Eder, and J. H. Bragdon. 1955. The distribution and chemical composition of ultracentrifugally separated lipoproteins in human sera. J. Clin. Invest. 34:1345-1353.

22. Goldstein, J. L., S. K. Basu, and M. S. Brown. 1983. Receptormediated endocytosis of low density lipoprotein in cultured cells. Methods Enzymol. 98:241-260.

23. Kovanen, P. T., M. S. Brown, and J. L. Goldstein. 1979. Increased binding of low density lipoprotein to liver membranes from rats treated with 17-ethinyl estradiol. J. Biol. Chem. 254:11367-11373.

24. Kovanen, P. T., D. W. Bilheimer, J. L. Goldstein, J. J. Jaramillo, and M. S. Brown. 1981. Regulatory role for hepatic low density lipoprotein receptors in vivo in the dog. Proc. Natl. Acad. Sci. USA. 78:1194-1198.

25. Harders-Spengel, K., C. B. Wood, G. R. Thompson, N. B. Myant, and A. K. Soutar. 1982. Difference in saturable binding of low density lipoprotein to liver membranes from normocholesterolemic subjects and patients with heterozygous familial hypercholesterolemia. Proc. Natl. Acad. Sci. USA. 79:6355-6359.

26. Han, J. H., C. Stratowa, and W. J. Rutter. 1987. Isolation of full-length putative rat lysophospholipase cDNA using improved methods for mRNA isolation and cDNA cloning. Biochemistry. 26:1617-1625.
27. Chirgwin, J. M., A. E. Przybyla, R. J. MacDonald, and W. J. Rutter. 1979. Isolation of biologically active ribonucleic acid from sources enriched in ribonuclease. Biochemistry. 18:5294-5299.

28. Aviv, N., and P. Leder. 1972. Purification of biologially active globin messenger RNA by chromatography on oligothymidylic acidcellulose. Proc. Natl. Acad. Sci. USA. 69:1408-1412.

29. Simonet, W. S., and G. C. Ness. 1988. Transcriptional and post transcriptional regulation of rat hepatic 3-hydroxy-3-methylglutarylcoenzyme A reductase by thyroid hormones. J. Biol. Chem. 263:12448-12453.

30. Gardiner, M. J., and D. G. Altman. 1989. Calculating confidence intervals for regression and correlation. In Statistics with Confidence. M. J. Gardner and D. G. Altman editors. British Medical Association (BMA), London WCIH 9JR. 34-39.

31. Rajavoshisth, T. B., A. K. Taylor, A. Ali, K. L. Swenson, and A. J. Lusis. 1989. Identification of a zinc finger protein that binds to the sterol regulatory element. Science (Wash. DC). 245:640-643.

32. Biel, F. U., G. L. Vega, P. A. Ma, A. Garg, and S. M. Grundy. 1988. Lipoprotein kinetics in beta-sitosterolemia. Arteriosclerosis. 8:587a.

33. Boberg, K. M., J.-E. Åkerlund, and I. Björkhem. 1989. Effect of sitosterol on the rate-limiting enzymes in cholesterol synthesis and degradation. Lipids. 24:9-12.

34. Brown, M. S., and J. L. Goldstein. 1974. Suppression of 3-hydroxy-3-methylglutaryl coenzyme $A$ reductase activity and inhibition of growth of human fibroblasts by 7 keto-cholesterol. J. Biol. Chem. 249:7306-7314.

35. Nguyen, L., G. Salen, S. Shefer, V. Shore, G. S. Tint, and G. Ness. 1990. Unexpected failure of bile acid malabsorption to stimulate cholesterol synthesis in sitosterolemia with xanthomatosis: comparison with lovastatin. Arteriosclerosis. 10:289-297. 